The most reliable indication of primary hyperparathyroidism is the repeated finding of a raised plasma calcium. Some still take a value of $11.0 \mathrm{mg} / 100 \mathrm{ml}$ as the upper limit of normal in adults, but mostly a lower value is accepted. In Oxford for some time we have considered a fasting reading over $10.5 \mathrm{mg} / 100 \mathrm{ml}$ as suspicious of hypercalcaemia, particularly in patients with renal stone. In Cambridge the upper limit of normal is $10.7 \mathrm{mg} / 100 \mathrm{ml}$ and 7 of the 19 patients with renal stones showed levels of 10.6 and $10.7 \mathrm{mg} / 100 \mathrm{ml}$. It seems possible that the 4 in whom hyperparathyroidism was later proved with plasma calcium levels of more than 10.7 $\mathrm{mg} / 100 \mathrm{ml}$ on provocative testing might have been considered to have shown hypercalcaemia before the testing which effectively raised the blood calcium.

The provocative test by phosphate deprivation and administration of chlorothiazide should prove useful in the diagnosis of "borderline" hyperparathyroidism in the future, and the authors are to be congratulated. The question is raised, however, what should be taken to be the normal range of blood calcium?-I am, etc.,

Milo Keynes

Oxford

1 Kevnes, W. M., Barnes, B. A., and Cope, O.,

MacFadyen, I. J., Nordin, B. E. C.. Smith, D. A., Wayne, D. J., and Ra

Eisenberg, E. in Parathyroid hormone and Thyrocalcitonin (Calcitonin), ed. R. V. Talmage and L. F. Belanger, pp. 465-474.

Eisenberg, E. Fournal of Clinical Endocrinology and Metabolism, 1968, 28,651.

\section{Folic Acid in Epilepsy}

SIR,-Trials of folic acid treatment in patients with epilepsy have been unsatisfactory for two reasons: (a) many trials have been poorly designed or uncontrolled, and (b) the measurement of fit freauency and mental state is, at best, unreliable. Even at a residential centre the recording of fits during the normal daily routine is usually haphazard and unreliable. Dr. Richard Grant and Dr. Olga Stores (12 December, p. 644) say little of the accuracy of their records of patients' fits. If they consider their data and classification of fits reliable it is surprising that they overlooked the significant increase in "tvpe A" fits (grand mal with definite tonic/clonic convulsions) in patients receiving folic acid, compared with those receiving placebo. During the first 26 weeks of treatment 11 patients on folic acid (Table II) showed an increase in "type A" fits, whereas 12 had a decrease or no change. In the placebo group the corresponding figures were 4 and 21 . In a $2 \times 2$ contingency table these totals produce a $\chi^{2}$ value of $4 \cdot 3$ $(p<0 \cdot 05)$. In Table III the calculation of a $t$ value based on the difference in the mean number of attacks is meaningless when the scatter of individual fit scores is so great (0-239 in the control period of the folic acid treated group). Thus, some patients are contributing much greater weight to the mean than others. This might have been avoided by converting each patient's fit score while on treatment to a percentage of the score during the control period.

Recent metabolic studies ${ }^{1}$ suggest that folic acid treatment lowers the serum level of phenytoin by altering the metabolism of this drug. It is unfortunate that patients who had serum phenytoin levels of over $25 \mu \mathrm{g} / \mathrm{ml}$ were excluded from this trial, or stabilized beforehand, for it is these patients who might have shown the greatest change in fit frequency and mental state with folic acid treatment.

A further point which seems not to have been considered in this, or any previously reported trial, is the spontaneous variation of routine serum folate estimations. Thus many patients will be wrongly classified on the results of a single determination, and probablv many patients used in clinical trials of folic acid have not been truly folate depleted. Our recent experience at this hospital is that most epileptic patients with a low serum folate level have a low red cell folate level in addition, suggesting a state of true deficiency. The red cell folate is considered to be a more reliable test for chronic folate depletion, ${ }^{2}$ and it would seem preferable to select patients for a folic acid trial using this criterion.

Nevertheless, this present study, and previous placebo controlled trials of folic acid therapy in epilepsy, ${ }^{3-4}$ should have been sensitive enough to demonstrate the dramatic changes in mental state and fit frequency which have been claimed by Reynolds. ${ }^{5}$ None of these trials has shown such an effect, and the only support for these claims comes from uncontrolled obser vations. However, one cannot lightly dismis well documented case reports, such as that of Chanarin et al. ${ }^{6}$ Future work should be concentrated on identifying folate-depleted patients more carefully and studying a few in depth, with intensive E.E.G. studies sup plementing records of fits.-I am, etc.,

Alan Richens

Division of Clinical Pharmacology

St. Bartholomew's Hospital,

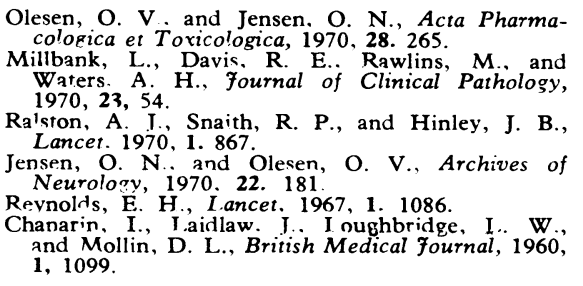

\section{Chromosome Aberrations after Exposure to Ultrasound}

SIR,-Chromosomes of human lymphocvtes cultured after exposure to ultrasound (Slade and Coakley) ${ }^{1}$ showed damage similar to that reoorted by $\mathrm{Mr}$. I. J. C. MacIntosh and Dr. D. A. Davey (10 October, p. 92) However, on changing the technique of irradiation the damage was no longer observed.

Lvmphocvtes suspended in TC 199 growth medium were irradiated in heatsealed polythene bags in a plane field at $1 \mathrm{mHz}$ at intensities from $3-45 \mathrm{watt} / \mathrm{cm}^{2}$ for 20 sec. Of 60 cells containing 46 chromosomes examined after culturing for $72 \mathrm{hr}, 26 \mathrm{had}$ aberrations ( 21 chromatid and 16 chromo some breaks or gaps). Damage was no dependent on sonic intensity. The control sample did not grow. In a second experiment in the same intensity range 24 cells had aberrations (24 chromatid and 7 chromo- some) in the 116 cells examined. A similarly handled but unsonicated control had five cells with aberrations in the $\mathbf{4 0}$ examined. In contrast, whole blood exposed to ultrasound at similar intensities showed one chromatid break in 30 cells after $72 \mathrm{hr}$, while 136 cells had only one break after $50 \mathrm{hr}$, compared with one in 90 control cells. The disappearance of the effect in whole blood suggests that chromosome damage was not caused by the direct action of ultrasound on the cells.

Subsequently irradiation of whole blood with pulsed ultrasound in an aluminium cylinder with Saran foil (Dow Corning) windows, at $1.0,2.5$ and $3.0 \mathrm{mHz}$ for $1 \mathrm{hr}$, pulse width $60-200 \mu \mathrm{sec}$, duty cycle 0.25 $0 \cdot 1$, peak pulse intensities up to 320 watt $/ \mathrm{cm}^{2}$, showed one abnormality in 270 cells as against one in 60 of the controls after $48 \mathrm{hr}$ growth.

The large number of chromatid aberrations found by $\mathrm{Mr}$. MacIntosh and $\mathrm{Dr}$. Davey and ourselves is remarkable considering that the cells were irradiated at the early $G_{1}$ stage of their cycle. On $x$-irradiation of lymphocytes chomatid breaks arise from damage in the later $S$ and $G_{2}$ stages only. ${ }^{2}$ Normal cells harvested after $72 \mathrm{hr}$ are in the second or third division, since irradiation and chromatid breaks arising from any indirect effect of ultrasound at the moment of irradiation would not still be present after 72 hr unless the first mitosis was considerably delayed by the sonication.

Agents causing chromatid breaks by misreplication during culture include viruses, Mycoplasma, and chemical mutagens. ${ }^{3}$ The persistence of the effect in the cultures treated by $\mathrm{Mr}$. MacIntosh and Dr. Davey suggest that a chemical rather than a biological agent may be operating. The disappearance of the effect in whole blood mav be due to the suppression of ultrasonic cavitation and its accompanying free radicals, but this is unlikely since bubbles, usually associated with cavitation, were not visible under our conditions, and radioactive thvmidine uptake experiments showed no drastic reduction in cell population. Again, the peak intensity used by $\mathrm{Mr}$. MacIntosh and Dr. Davey, is $20 \mathrm{~m}$ watt $/ \mathrm{cm}^{2}$ (personal communication from Smith Kline, the manufacturers), or an acoustic pressure of 0.25 bars, which is lower by a factor of three than the lowest pressure recorded for the onset of cavitation in the $\mathrm{mHz}$ region. ${ }^{4}$

The high incidence of aberrations in our control sample in tissue culture medium in the polythene bag could be due to the release of "toxins" from the containers. The disappearance of the effect in whole blood may be due to the detoxifying effect of whole blood. The release of an enzyme inactivating material from a rubber window of an ultrasonic chamber has been reported by Macleod and Dunn. ${ }^{5}$ Sonication releases ultraviolet absorbing material from dialysis tubing irradiated under the same conditions as the lymphocytes.

The similarity of chromosome damage found by Mr. MacIntosh and Dr. Davey and ourselves suggests that it may be due to the same cause. The high number of chromatid aberrations after $72 \mathrm{hr}$ suggests that a chemical agent, possibly released from the container or due to cavitation, may have been in the culture. The disappear- 
ance of the effect in whole blood makes it susception in patients with cystic fibrosis unlikely that the damage arose from the has also been noted in this clinic.

direct interaction of the sound with the cell.

This work was supported by a grant from the M.R.C.

-We are, etc.,

\section{W. T. COAKLEY}

D. E. Hughes

Microbiology Department,

University College,
Cardiff

J. S. SLADE

K. M. LAURENCE

Department of Child Health,

Welsh National School of Medicine,
Penarth, Glam

1 Slade, J. S., and Coakley, W. T., in preparation. Heddle, J. A., Evans, H. J., and Scott David, in Human Radiation Cytogenetics. Ed. Evans, H. J., Amsterdam, North Holland. 1967 . 3 United Nations General Assembly, Report of the United Nations. Scientific Committee on the
Effects of Atomic Ratiarion, 24th Session, Suppl. Effects of Atomic Ratiarion, 24th Session,
No. 13 (A/7613) New York, U.N., 1969.

+ Barger, J. E.. Thresholds of Acoustic Cavitation, Acoustics Research Laboratories, Harvard Uni-

versity, Technical Memorandum No. 57, 1964 .
Macleod, R. M., Dunn, F., fournal of the
Acoustical Society of America, 1966, 40, 1202.

\section{Problems of Rectal Prolapse}

SIR,-Y Your leader on this (14 November, p. 381) sadly fails to lead. May I respectfully suggest, firstly, that all the many reports indicate that the Ivalon wrap that I presented on a film on numerous occasions before publishing in $1959^{1}$ is simple, safe, and successful? Recurrences of prolapse are in the low single figures per cent. and no foreign body remains, since the material disintegrates within about a year. Secondly, all patients with complete prolapse are, of necessity, incontinent before operation. The operation I described does nothing to make things worse but permits whatever sphincteric action exists to operate to the best advantage.

Your leader rightly concludes that the aetiology and treatment of anal incontinence remain "important challenges" but the blanket statement that "incontinence had improved in about $60 \%$ of cases" does nothing to helo meet that challenge, since it makes no analysis of either the preoperative condition or the type of operation employed.

Hoylake, Cheshire

Charles Wells

1 Wells, C., Proceedings of the Royal Society of

SIR,-Your leading article (14 November, p. $381)$ states that this condition occurs most commonly in infancy and old age. However, no mention was made of cystic fibrosis as a cause of rectal prolapse in infancy. Kulczycki and Shwachman ${ }^{1}$ reported that this symptom was the initial complaint in 16 patients with cystic fibrosis and that $22.6 \%$ of 386 patients with cystic fibrosis gave a history of rectal prolapse. The National Cystic Fibrosis Research Foundation's guide to the diagnosis and management of cystic fibrosis states that cystic fibrosis is the commonest cause of prolapse of the rectum in the paediatric age group in the United States. The recent observations you refer to showing that rectal prolapse is an intussusception is of considerable interest, as an increased incidence of other forms of intus-
The diagnosis of cystic fibrosis should always be considered in infants and children with rectal prolapse and a sweat test is advisable if there is no obvious cause. Treatment is with a low-fat diet, pancreatic enzyme supplements, and measures to improve the pulmonary condition. Surgery is rarely required.-We are, etc.

\section{JOHN LLOYD-STILL}

KON-TAIK KHAW HARRY SHWACHMAN Children's Hospital Medical Center Boston, Massachusetts, U.S.A.

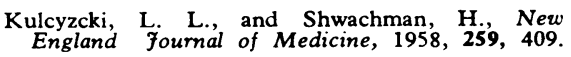

\section{Haemoptysis in Cystic Fibrosis}

SIR,-Your recent leader "Haemoptysis in Cystic Fibrosis" (19 December, p. 702) is timely, for there is no doubt that children suffering from this disease are living longer and are presenting with previously rarely seen complications. However, this is a rare disease and the experience of any one surgeon in dealing with severe haemoptysis in these patients is likely to be limited, and for this reason a brief note on the treatment of

A boy of 17, known to suffer from fibrocystic disease of the lungs since early life, was referred with severe haemoptysis in February this year. At that time he was expectorating up to $300 \mathrm{ml}$ of bright red blood daily. An intelligent boy, he was sure that this was coming from the base of his right lung, for prior to each episode of haemoptysis he felt the blood bubbling at the back of his right lower chest. $\mathrm{He}$ was treated conservatively, and fortunately after two weeks, during which time he received 8 units of blood, this symptom subsided. However, he was readmitted in October 1970 with further severe haemoptysis, and on this occasion he was producing up to $800 \mathrm{ml}$ daily. He was now very anaemic and demoralized, and for this reason surgery was considered but while awaiting an elective operation he had massive haemoptysis of $1,500 \mathrm{ml}$ of bright red blood. It was assumed that the bleeding was originating from a bronchiectatic right lower lobe and that the blood was coming from bronchial arteries rather than pulmonary arteries. Emergency right thoracotomy was undertaken. The lung was boggy and pale but the striking feature was the hypertrophied bronchial artery, coursing along the lower edge of the right main bronchus. This was almost the size of a normal brachial artery, $0.5 \mathrm{~cm}$ in diameter, giving off a small ascending and a large descending tortuous artery to the right lower lobe. The bronchial artery was divided between ligatures. Postoperatively the haemoptysis ceased dramatically although there was a further small episode one week postoperatively. He developed a severe pulmonary infection, which responded to appropriate antibiotics, and was discharged well four weeks after operation. This appears to have been a successful operative procedure, although it is likely that adventitious and equally large bronchial arteries will in due course develop and may produce further haemoptysis.

Contrary to the gloomy attitude of some disabled. This patient leads an otherwise fairly normal life.

I thank Dr. Beryl Corner for asking me to treat this patient.-I am, etc.,

G. KEEN

Bristol Royal Infirmary, such a patient may be of interest. writers, these patients are not necessarily
Resuscitation Too Late

SIR,-This week I saw with my own eyes for the first time the relatively recent syndrome of a patient who was resuscitated too late-that is, after prolonged cerebral anoxia. The general practitioner is in a great state of isolation compared to those who work in hospitals. Many general practitioners who, like myself, qualified a couple of decades back have never even seen these new man-made syndromes unless they stray on them by chance, as I did. Nevertheless, unless certain criteria are established and made known, we ourselves may be guilty of resuscitating people too late, with all the anguish that results.

I feel it is long overdue that the profession was given the chance to create a new platform on which new developments may be debated up and down the country together with church leaders and others concerned with our presentday ethics. Even the question of euthanasia must constantly, by implication, be reassessed so that we may have the consolation that there exists the widest possible consensus of opinion that is constantly under review. We can no longer escape these issues and it is cowardly to do so.-I am, etc.,

Eleonore M. EtTlinger

Little Cornard,

\section{Skin Disease and the Gut}

SIR,-Several important points are raised by Dr. E. J. Moynahan's interesting letter (28 November p. 559).

The first concerns the apparent difference in the incidence of rashes in coeliac disease of children and adults. We ourselves have also noticed this unexplained differencel and the general feeling that rashes are rare in childhood coeliacs has been supported by a recent detailed study of children with coeliac disease."

The second point concerns the incidence of the more specific rash of dermatitis herpetiformis in these patients. From replies to a recent national questionnaire sent out through the Coeliac Society it is interesting that of the coeliacs who had a rash in about $10 \%$ this was in fact dermatitis herpetiformis. We have in our care three such patients with proved glutensensitive coeliac disease who have been referred to us with a rash which has turned out to be dermatitis herpetiformis and several similar cases have been reported in Britain. ${ }^{3-6}$ So $\mathrm{far}$. however, no study of the bowel in juvenile dermatitis herpetiformis has been published.

Important though the association of dermatitis herpetiformis with clinical coeliac disease is, this is not really our message. ${ }^{7-13}$ In our original paper ${ }^{7}$ we reported that two-thirds of patients with dermatitis herpetiformis had on biopsy a jejunal mucosal appearance indistinguishable from that found in patients with coeliac disease or "idiopathic steatorrhoea." This is a separate issue from the occurrence of clinical coeliac disease and indeed most of our patients, including those with the most severe changes on mucosal biopsy, have no symptoms and some of them have no biochemical evidence of malabsorption either. It is therefore irrelevant to say, as Dr. Moynahan and many others have said, that patients with dermatitis herpetiformis have no symptoms or signs and therefore do not have an enteropathy-only jejunal biopsy in these patients will show these severe mucosal changes. Moreover, 